\title{
Approach to a child with Multisystem Inflammatory Syndrome associated with COVID-19. Recommendations by the Polish Paediatric Society Expert Group. Update - February 2021
}

\author{
Magdalena Okarska-Napierała', Kamila Ludwikowska², Teresa Jackowska³, Janusz Książyk4, \\ Piotr Buda ${ }^{4}$, Artur Mazur ${ }^{5}$, Leszek Szenborn'르, Bożena Werner ${ }^{6}$, Jacek Wysocki ${ }^{7}$, Ernest Kuchar ${ }^{1}$ \\ 'Department of Pediatrics with Clinical Decisions Unit, Medical University of Warsaw, Warsaw, Poland \\ ${ }^{2}$ Department of Pediatric Infectious Diseases, Wroclaw Medical University, Wroclaw, Poland \\ ${ }^{3}$ Department of Pediatrics, The Medical Centre of Postgraduate Education, Warsaw, Poland \\ ${ }^{4}$ Department of Pediatrics, Nutrition and Metabolic Diseases, The Children's Memorial Health Institute, Warsaw, Poland \\ ${ }^{5}$ Department of Pediatrics, Pediatric Endocrinology and Diabetes, University of Rzeszow, Rzeszow, Poland \\ ${ }^{6}$ Department of Pediatric Cardiology and General Pediatrics, Medical University of Warsaw, Warsaw, Poland \\ ${ }^{7}$ Department of Preventive Health, Poznan University of Medical Science, Poznan, Poland
}

\section{ABSTRACT}

\begin{abstract}
Multisystem Inflammatory Syndrome in Children (MIS-C) is a new clinical entity occurring in children and young adults, which is associated with the SARS-CoV-2 infection. The first cases of MIS-C were diagnosed in Poland in May 2020. Since October 2020, a significant increase in the incidence of this new disease has been observed in Poland, reflecting the increased incidence of COVID-19 in the paediatric population. MIS-C develops as a result of dysregulation of the immune system occurring 4 weeks after the SARS-CoV-2 infection. Diagnosis is based on the following criteria: a set of clinical features (including fever and signs of multiple organ damage) and elevated inflammatory markers, with exclusion of other causes. The most common complications involve the cardiovascular system: acute myocardial damage with reduced left ventricular ejection fraction, shock, and coronary artery abnormalities and arrhythmias. Mortality in Western Europe and the United States is around $1-2 \%$. Appropriate management, including vital function support and immunomodulatory treatment, allows for a quick recovery in the vast majority of patients. This document is an updated guideline for the diagnostic and therapeutic management of children with suspected MIS-C in Poland. The most important changes concern treatment, steroid therapy, and antiplatelet therapy in particular.
\end{abstract}

KEY WORDS:

Kawasaki disease, MIS-C, PIMS-TS, hyperinflammation.

\section{INTRODUCTION}

Multisystem Inflammatory Syndrome in Children (MIS-C) or Paediatric Inflammatory Multisystem Syndrome temporally associated with severe acute respiratory syndrome coronavirus 2 (SARS-CoV-2) (PIMS-TS)
(ICD-10 U10.9) is a new clinical entity, which was first described in May 2020 [1, 2]. So far, published data have shown that MIS-C develops about 4 weeks after (usually asymptomatic or oligosymptomatic) SARS-CoV-2 infection, as a result of immune dysregulation [3]. It can be estimated from the United States (U.S.) data that about

\section{ADDRESS FOR CORRESPONDENCE:}

Magdalena Okarska-Napierała, MD PhD, Department of Paediatrics with the Observation Unit of the Medical

University of Warsaw, Żwirki i Wigury 63A, 02-091 Warsaw, Poland, tel. +48 2231790 33,

e-mail: magda.okarska@gmail.com 
1/1000 children with SARS-CoV-2 develop MIS-C (4). MIS-C is an acute and potentially dangerous inflammatory syndrome, leading to cardiac complications (acute myocarditis with reduced left ventricular ejection fraction in particular) or shock. Recently, attention has also been drawn to electrocardiac abnormalities, which occur in up to $60 \%$ of patients [5]. Effective and timely treatment allows for full recovery within a few days in most patients. The most common permanent complications include coronary aneurysms, which may develop independently of the phenotype and severity of the disease [3]. In the U.S. population, where most cases have been reported so far, mortality rates are 1-2\% despite treatment [4].

The first cases of MIS-C occurred in Poland in May 2020. Since October 2020, an increase in the incidence of MIS-C in Poland has been observed, which corresponds with the increased incidence of coronavirus disease 2019 (COVID-19) [6]. Data collected so far have shown that the rates of complications requiring intensive paediatric care are lower in Poland than those reported in U.S., British, and French publications. So far (as of 19 January 2021) no deaths due to MIS-C have been reported in our country.

This document is an update of the diagnostic and therapeutic guidelines for children with suspected MIS-C in Poland. It is based on the following:

- a review of current reports on MIS-C,

- data from the Polish nationwide register of children with inflammatory diseases (MOIS CoR: www.pimsudzieci.pl) [6].

As growing data on the Polish population continues to be collected and new relevant information about MIS-C becomes available, this document will be further updated.

\section{A SUMMARY OF CHANGES TO THE FIRST VERSION OF THE GUIDELINES}

1. We considered outpatient monitoring of children in good overall condition, who have not yet met MIS-C diagnostic criteria, but in whom the epidemiological circumstances and the clinical picture suggest that this diagnosis may be confirmed in the following days, acceptable.

2. We emphasised that antibiotic therapy in children with MIS-C should be reserved for patients with doubtful diagnosis, especially those in a serious condition, and that it should not be used routinely. There are also no indications to continue antibiotic therapy in children with an unambiguous diagnosis of MIS-C.

3. We proposed using the maximum intravenous immunoglobulin (IVIG) dose of $100 \mathrm{~g}$ when the availability of IVIG is limited.

4. In first-line refractory patients, a second IVIG infusion is not recommended unless the clinical picture indicates Kawasaki disease (KD). The differentiation between MIS-C and KD is not always easy and unambigu- ous; therefore, we have included a table that summarises the main differences between these 2 clinical entities.

5. We have modified the glucocorticosteroid (GC) treatment strategy. We suggest starting treatment with methylprednisolone at a dose of $2 \mathrm{mg} / \mathrm{kg} / \mathrm{day}$, and reserving pulse therapy for children with a particularly severe course of the disease or those unresponsive to treatment with lower GC doses. Additionally, we presented arguments for setting the maximum daily dose of $60 \mathrm{mg}$ prednisone when a $2 \mathrm{mg} / \mathrm{kg} /$ day regimen is used - the decision to use higher doses should be made individually. We also suggest GC dosing for ideal body weight, which is of particular importance in overweight and obese children.

6. We have restricted the indications for an anti-inflammatory dose of acetylsalicylic acid (ASA). The antiinflammatory dose of ASA should be used when the clinical picture supports a Kawasaki disease diagnosis. Children on GCs should not receive the anti-inflammatory ASA dose.

7. The maximum daily antiplatelet dose of ASA is $75 \mathrm{mg}$.

\section{DEFINITION AND CLINICAL PICTURE OF MIS-C}

\section{Diagnosis of MIS-C}

\subsection{Definition}

Currently, several definitions of MIS-C function in different countries $[2,7,8]$. Despite minor differences, they are all based on $\mathbf{6}$ criteria, which we propose as a cornerstone for the diagnosis of MIS-C in Poland. Criteria 1-5 must be met to diagnose MIS-C. Criterion 6 is not obligatory - in the case of a clinical picture strongly indicative of MIS-C, especially in a patient in a worsening or severe condition, this diagnosis should be considered even if criterion 6 is not met. Table 1 presents the diagnostic criteria for MIS-C.

A characteristic constellation of laboratory abnormalities is useful in the diagnosis:

- extremely high inflammatory markers (the cut-off point for individual parameters is not determined, but CRP is usually higher than $100 \mathrm{mg} / \mathrm{l}$ ),

- lymphopaenia,

- minor anaemia,

- hypoalbuminaemia,

- hyponatraemia,

- high levels of myocardial damage markers: B-type natriuretic peptide (BNP) or N-terminal-prohormone BNP (NT-proBNP), troponin I [3, 4].

1.2. Subsequent MIS-C symptoms appear gradually, usually with dominant gastrointestinal symptoms in the first days. For this reason, some children with MIS-C are operated on for suspected appendicitis. In the current epidemiological situation, children qualified for appen- 
TABLE 1. Multisystem inflammatory syndrome in children (MIS-C) diagnostic criteria

\begin{tabular}{|l|l|}
\hline 1. Age & $\begin{array}{l}\text { Children (0-18 years old) } \\
\text { Usually school-aged children, with median age of } 8.5 \text { years }\end{array}$ \\
\hline 2. Fever $\geq 3$ days & $\begin{array}{l}\text { Obligatory criterion } \\
\text { There are no defined threshold values, but usually body temperature is }>38.5^{\circ} \mathrm{C}\end{array}$ \\
\hline $\begin{array}{l}\text { 3. High inflammatory } \\
\text { markers }\end{array}$ & $\begin{array}{l}\text { Elevated: CRP, procalcitonin, ESR, fibrinogen, LDH, D-dimer, ferritin } \\
\text { There are no defined threshold values, but usually inflammatory markers are substantially increased }\end{array}$ \\
\hline $\begin{array}{l}\text { 4. Multisystem ( } \geq 2) \\
\text { organ involvement }\end{array}$ & $\begin{array}{l}\text { gastrointestinal: severe abdominal pain, diarrhoea, nausea, vomiting; } \\
\text { cardiovascular: hypotension, shock, myocarditis (based on echocardiographic findings or laboratory markers), } \\
\text { coronary artery aneurysms, pericarditis, arrhythmias } \\
\text { neurological: lethargy, irritability, aseptic meningitis, peripheral palsy/paralysis, severe headache } \\
\text { respiratory: cough, dyspnoea, pneumonia, pleural effusion, chest pain } \\
\text { mucocutaneous: rash (polymorphic), conjunctival injection, strawberry tongue, dry, red lips, oedema of hands } \\
\text { and feet } \\
\text { renal: acute kidney injury, oliguria, sterile leukocyturia } \\
\text { coagulopathy }\end{array}$ \\
\hline $\begin{array}{l}\text { 5. No alternative } \\
\text { plausible diagnoses }\end{array}$ & $\begin{array}{l}\text { Following should be considered within differential diagnosis: } \\
\text { Infectious and toxic causes, e.g. sepsis, toxic shock syndrome, acute viral infection } \\
\text { Acute appendicitis, peritonitis } \\
\text { Rheumatologic/oncologic disorders, inflammatory bowel disease }\end{array}$ \\
\hline $\begin{array}{l}\text { 6. Positive for current } \\
\text { or recent SARS-CoV-2 } \\
\text { infection }\end{array}$ & $\begin{array}{l}\text { positive RT-PCR } \\
\text { positive antigen test } \\
\text { positive serology test } \\
\text { exposure to confirmed COVID-19 case within the 4-8 weeks prior to the onset of symptoms }\end{array}$ \\
\hline
\end{tabular}

COVID-19 - coronavirus disease 2019; CRP - C-reactive protein; ESR - erythrocyte sedimentation rate; LDH - lactate dehydrogenase; RT-PCR - real time-polymerase chain reaction; SARS-COV-2 - severe acute respiratory syndrome coronavirus 2

Positive laboratory results for SARS-CoV-2 support the diagnosis, but negative results do not exclude it. On the other hand, positive SARS-CoV-2 tests may be coincidental in a child with another cause of hyperinflammatory state.

TABLE 2. Characteristics differentiating between Kawasaki disease (KD) and multisystem inflammatory syndrome in children (MIS-C) [9]

\begin{tabular}{|l|c|c|}
\hline Parameter & MIS-C & KD \\
\hline Age & 8.5 years old & 2-3 years old (85\% are $<5$ years old) \\
\hline Lymphocyte count & Decreased & Normal \\
\hline Haemoglobin concentration & Decreased & Normal or mildly decreased \\
\hline Platelet count & Decreased or normal & Normal or increased \\
\hline CRP concentration & Substantially increased & Normal \\
\hline Ferritin concentration & Increased & Normal or increased \\
\hline BNP or NT-proBNP concentration & Substantially increased & Usually normal \\
\hline Troponin concentration & Often increased & Usually absent \\
\hline Features of myocarditis, decreased left ventricular contractility & Often present & Usually absent \\
\hline Severe gastrointestinal involvement & Frequent & \\
\hline
\end{tabular}

CRP - C-reactive protein; BNP - B-type natriuretic peptide; NT-proBNP - N-terminal pro B-type natriuretic peptide

dectomy should be preoperatively consulted with a paediatrician to exclude MIS-C.

\subsection{MIS-C in ICD-10}

MIS-C was initially referred to as Kawasaki disease-like (KD-like) syndrome.

However, it is currently known that although some patients with MIS-C also meet the diagnostic criteria for Kawasaki disease, it has been recognized as a separate, novel clinical entity $[3,9]$. Table 2 shows differences between KD and MIS-C. In October 2020, the syndrome was incorporated in the extended ICD-10 classification under code U10.9: Multisystem inflammatory syndrome associated with COVID-19, unspecified.

\section{Hospitalisation}

2.1. Management in a patient with a strong suspicion of MIS-C

All patients suspected of MIS-C should be hospitalized, ideally in a facility with a paediatric intensive care unit and an option of cardiological consultation [10]. They do not have to be hospitalised in special COVID-19 units.

The data collected so far show that a significant percentage of patients meeting the above diagnostic criteria 
TABLE 3. Recommended laboratory evaluation in patients with multisystem inflammatory syndrome in children (MIS-C)

\begin{tabular}{|c|c|}
\hline $\begin{array}{l}\text { Microbiologic tests } \\
\text { - blood culture } \\
\text { - SARS-CoV-2 RT-PCR serology } \\
\text { - Other, depending on clinical } \\
\text { circumstances }\end{array}$ & $\begin{array}{l}\text { Inflammatory markers } \\
\text { - CRP, procalcitonin } \\
\text { - ESR } \\
\text { - ferritin } \\
\text { - LDH }\end{array}$ \\
\hline $\begin{array}{l}\text { Complete blood count } \\
\text { Blood group } \\
\text { Blood gas with lactate }\end{array}$ & \multirow{2}{*}{$\begin{array}{l}\text { 0ther biochemical markers } \\
\text { - albumin } \\
\text { - } \text { sodium (Na), potassium (K) } \\
\text { - triglycerides } \\
\text { - } \text { CK } \\
\text { - } \text { NT-proBNP (or BNP), } \\
\text { troponin } \\
\text { - amylase, lipase } \\
\text { - creatinine, urea } \\
\text { - } \text { AST, ALT, GGTP, bilirubin }\end{array}$} \\
\hline $\begin{array}{l}\text { Coagulation test } \\
\text { - INR, APTT } \\
\text { - fibrinogen } \\
\text { - D-dimer }\end{array}$ & \\
\hline
\end{tabular}

SARS-CoV-2 - severe acute respiratory syndrome coronavirus 2; RT-PCR - real time-polymerase chain reaction; INR - international normalized ratio; APTT - activated partial thromboplastin time; $C R P$ - C-reactive protein; $E S R$ - erythrocyte sedimentation rate; $L D H$ - lactate dehydrogenase; $C K$ creatine kinase; $B N P$ - B-type natriuretic peptide; NT-proBNP - N-terminal-pro B-type natriuretic peptide; $A S T$ - aspartate transaminase; ALT - alanine transaminase; GGTP - gamma-glutamyl transpeptidase

for MIS-C develop left ventricular failure or shock (about $50 \%$ according to U.S. and Western European data). Sudden deterioration of the clinical condition usually occurs after 5-6 days of fever. However, waiting for the patient to be transferred to an appropriate hospital should not be a reason to postpone treatment. Patients with suspected MIS-C should be under constant medical supervision due to the possibility of a sudden deterioration of vital functions.

\subsection{Management in patients with a weak suspicion} of MIS-C

Different management may be needed in patients in a good clinical condition at medical consultation, who do not meet the diagnostic criteria for MIS-C (e.g. low inflammatory markers or no evidence of multiorgan involvement), but the epidemiological circumstances and exclusion of other aetiological factors lead to suspicion of an inflammatory disease secondary to SARS-CoV-2 infection. Because MIS-C symptoms may develop gradually, these patients require close medical supervision as part of frequent follow-up visits. Vigilance and readiness to revise the diagnosis if additional clinical signs indicative of MIS-C occur or if the child's overall condition deteriorates are needed (see also "Special Circumstances" below).

\section{Isolation}

3.1. Until active SARS-CoV-2 infection has been ruled out (optimally negative real time-polymerase chain reaction [RT-PCR], and if not available, negative antigen test result), patients with MIS-C should be treated as COVID-19 patients with standard precautions in accordance with the procedures applicable in a given centre.

\section{Laboratory and imaging tests}

\subsection{Diagnosis for SARS-CoV-2}

Each patient should have a SARS-CoV-2 smear test performed (RT-PCR or an antigen test). Antibodies to SARS-CoV-2 should also be measured (especially in patients with negative upper respiratory smear).

\subsection{Microbiological and laboratory tests}

All children with suspected/diagnosed MIS-C should have the blood tests listed in Table 3 performed. The scope of microbiological diagnosis (e.g. urine and stool cultures, pharyngeal swab, virological tests) should depend on the clinical picture and diagnostic possibilities of a given centre.

\subsection{Cardiac tests}

All children with suspected MIS-C must undergo electrocardiography (ECG) and echocardiography (ECHO) [10, 11].

\section{RECOMMENDATIONS FOR CARDIAC MANAGEMENT}

1. The first ECHO should be performed as early as possible; coronary arteries should also be assessed because up to $25 \%$ of patients often develop abnormalities, including coronary aneurysms, in the first week of the disease.

2. The decision to repeat ECHO should depend on the cardiologist's indications and the affected child's clinical condition. Haemodynamically stable patients with no changes in the baseline cardiovascular assessment are recommended follow-up as follows:

- 7-14 days,

- 6 weeks,

- 6-12 months after symptom onset.

3. If baseline ECHO reveals abnormalities (decreased myocardial contractility [Ejection Fraction, EF], coronary artery dilatation/aneurysms, pericardial fluid), ECHO test should be repeated every 2-3 days during the acute phase, and daily in the case of myocardial involvement and hospitalization in an intensive care unit. In some cases, it may be necessary to perform computed tomography (to assess changes in the coronary arteries, including the presence of a coronary thrombus). Cardiovascular magnetic resonance imaging does not play basic role in the acute phase of MIS-C but may be used in selected patients as a follow-up after MIS-C (assessment of oedema, scarring, and ventricular function).

4. The first ECG should be performed as soon as possible after the diagnosis of MIS-C; follow-up ECG is indicated during further patient monitoring, especially in patients with evidence of myocardial damage. Patients with confirmed abnormalities in the electrical activity of the heart may also require 24-hour electrocardiogram Holter monitoring. 


\subsection{Other imaging modalities}

Most patients require a plain $\mathrm{P}-\mathrm{A}$ chest radiograph. Chest CT is performed in exceptional cases. Despite the absence of respiratory symptoms, imaging changes corresponding to inflammatory changes in the lungs (parenchymal densities, pleural fluid) can be expected.

The decision to perform abdominal imaging should depend on the clinical picture. If indicated, ultrasonography should be the first-line imaging modality [10]. In some patients with MIS-C, abdominal imaging may show thickened intestinal walls, radiological signs of appendicitis, thickened gallbladder walls, peritoneal fluid, and mesenteric lymphadenopathy.

\section{Treatment}

\subsection{General principles}

If possible, therapeutic decisions should be made by a multidisciplinary team, including specialists in infectious diseases, cardiology, rheumatology, haematology, and, possibly, a specialist in paediatric intensive care $[10,11]$.

Haemodynamic stabilization of the patient, including fluid therapy, should be performed according to generally accepted principles. It should be noted, however, that excessively aggressive fluid therapy may lead to pulmonary oedema in some patients with ventricular dysfunction. Echocardiographic assessment is particularly useful in fluid resuscitation because the inspiratory collapse of the inferior vena cava is a marker of hypovolaemia and an indication for fluid therapy, while reduced ejection fraction is a potential indication for the inclusion of catecholamines, and fluid therapy should be performed with caution. If pre-treatment echocardiography is not possible, attention should be paid to the clinical signs of cardiac overload and biochemical markers such as BNP or NT-proBNP.

During hospitalization, vital parameters (blood pressure, heart rate, saturation) should be monitored continuously or at 1-4-hour intervals, depending on the patient's condition, taking into account the risk of a rapid deterioration of the patient's condition 5-6 days after symptom onset [2].

\subsection{Antibiotic therapy}

In the initial phase, the clinical picture of MIS-C may resemble invasive infection, including sepsis, toxic shock syndrome, or other bacterial diseases (e.g. bacterial gastroenteritis, scarlet fever). Therefore, adequate empirical antibiotic therapy is indicated (depending on the presented clinical picture) in the event of diagnostic doubts, especially in patients with poor or worsening general condition. If toxic shock syndrome is suspected, ceftriaxone with clindamycin will be the optimal antibiotic therapy. Antimicrobial therapy should be continued until the diagnosis of MIS-C is established or, in exceptional cases, until negative microbiology is obtained [10].
It should be emphasized that when MIS-C is strongly suspected, antibiotic therapy should be discontinued, especially when it does not bring the expected results. Because high inflammatory markers in the course of MIS-C indicate immune dysregulation rather than bacterial infection, antibiotics are ineffective. Antimicrobials may be needed for nosocomial infections, mainly for children in intensive care, but should always be preceded by repeated microbiological analysis.

\subsection{Antiviral therapy}

Because MIS-C is a late immune complication of SARS-CoV-2 infection, antiviral treatment is not recommended. Antiviral treatment may be justified in very few cases, when the patient with severe COVID-19 meets the MIS-C criteria [10]. Remdesivir is the treatment of choice in such situations. Detailed indications and principles for its use are discussed in the guidelines published in Paediatric Review under the title "Management of a child with COVID-19. Recommendations for pediatricians and family medicine physicians in primary healthcare and hospital settings" [12].

\subsection{Immunosuppressive/immunomodulatory treat-} ment

Immunomodulatory therapy plays an essential role in the treatment of patients with MIS-C. Current knowledge does not yet allow for the formulation of strict recommendations. Immunosuppressive and immunomodulatory treatment should be introduced gradually, depending on the effects of the therapy used so far. The goal of treatment is to inhibit inflammation to avoid serious MIS-C complications in the form of myocardial damage, including coronary aneurysms. Symptomatic treatment may be sufficient in some patients with a mild, self-limiting disease (see below). The impact of treatment discontinuation on the risk of coronary aneurysms is currently unknown.

\subsubsection{IV immunoglobulin (IVIG) infusion at a dose} of $2.0 \mathrm{~g} / \mathrm{kg}$ is first-line therapy $[10,11]$

\section{Comments:}

A) Doses of IVIG are based on ideal body weight (IBW) [8], which is particularly important in adolescents, especially those with obesity or oedema:

- IBW in girls $[\mathrm{kg}]=($ height $[\mathrm{cm}]-100)-10 \%$ of this value,

- IBW in girls $[\mathrm{kg}]=($ height $[\mathrm{cm}]-100)-5 \%$ of this value.

In younger children with obesity/oedema, IBW can be determined based on the height percentile and body weight corresponding to the same percentile for age. In the case of limited availability, the IVIG dose may be reduced to $100.0 \mathrm{~g}$.

B) IVIG is given in a single 10-12-hour infusion or in divided doses, depending on the general condition, cardiovascular efficiency, and drug tolerance. IVIG should 
be administered with caution (i.e. the infusion should start at a slow rate; if necessary, divided doses may be given over 2-3 days) to patients with reduced cardiac ejection fraction. If pre-treatment cardiovascular evaluation is not possible, attention should be paid to the clinical signs of low cardiac output and biochemical indicators, such as BNP or NT-proBNP - the risk of cardiovascular overload and shock [11].

C) The second IVIG infusion is not recommended in patients unresponsive to first-line treatment [11]. Such management may be considered in children whose clinical picture indicates Kawasaki disease [10, 13, 14] (Table 2).

D) In severe symptoms of poor IVIG tolerance, such as headache, abdominal pain, nausea, vomiting, and fever, the rate of IVIG infusion should be reduced. Analgesics and antipyretics can also be included. In severe adverse effects, methylprednisolone can be administered simultaneously at a dose of 1-2 mg/kg. In an anaphylactic reaction or shock, administration of IVIG should be discontinued and standard anti-anaphylactic treatment and second-/third-line treatment should be introduced.

5.4.2. Glucocorticosteroids (GCs) are second-line drugs $[10,11]$

Indications for GCs [10]:

a) severe or deteriorating general condition*,

b) signs of shock ${ }^{*}$,

c) no improvement (persistent fever in particular) 24-

36 hours after completing IVIG infusion**,

d) age $<12$ months*,

e) the presence of coronary artery aneurysms in $\mathrm{ECHO}^{*}$,

f) anaphylactic reactions to IVIG,

g) unavailability of IVIG.

* indications for simultaneous use of IVIG and GCS

Lack of improvement after first-line treatment in MIS-C children is difficult to define. The recurrence of fever or other clinical symptoms or laboratory markers

TABLE 4. Immunomodulatory treatment in multisystem inflammatory syndrome in children (MIS-C)

\begin{tabular}{|l|l|}
\hline $\begin{array}{l}\text { Biologic } \\
\text { medication }\end{array}$ & Dosing \\
\hline Infliximab & $5-10 \mathrm{mg} / \mathrm{kg}$ in 2-hours infusion i.v. $(14,16)$ \\
\hline Anakinra & $\begin{array}{l}4-10 \mathrm{mg} / \mathrm{kg} / \text { day i.v. or s.c. in divided doses 6-12 } \\
\text { daily } \\
\text { with further dose tapering over 2-3 weeks. } \\
\text { ALT, AST should be monitored [17] }\end{array}$ \\
\hline Tocilizumab & $\begin{array}{l}\text { Body mass }<30 \mathrm{~kg} \rightarrow 12 \mathrm{mg} / \mathrm{kg} \text { 1-hour infusion } \\
\text { i.v. } \\
\text { Body mass } \geq 30 \mathrm{~kg} \rightarrow 8 \mathrm{mg} / \mathrm{kg} \text { 1-hour infusion } \\
\text { i.v. } \\
\text { (max. dose } 800 \mathrm{mg} \text { ) } \\
\text { ALT, AST, triglycerides should be monitored }\end{array}$ \\
\hline
\end{tabular}

i.v. - intravenously; s.c. - subcutaneously; AST - aspartate transaminase; ALT - alanine transaminase of increasing inflammation 24-36 hours after completing IVIG infusion is an indication for treatment escalation. However, the general condition might markedly deteriorate or new disease symptoms might develop on the first day after IVIG treatment. Second-line therapy should not be delayed in such cases. Such decisions must be made individually, preferably by a multidisciplinary team.

We suggest that steroid therapy be initiated with methylprednisolone at a dose of $2 \times 1 \mathrm{mg} / \mathrm{kg}$ (i.e. $2 \mathrm{mg} / \mathrm{kg} /$ day) in clinically stable patients. Once CRP normalization is achieved, oral steroid can be used, with gradual dose reduction over 2-3 weeks [13].

Data on the maximum daily dose of GCs in the treatment of MIS-C are missing. It should be noted that daily prednisolone doses of $60 \mathrm{mg}$ (48 $\mathrm{mg}$ of methylprednisolone) are associated with a significant increase in the risk of adverse drug reactions in the absence of significant additional therapeutic benefit. The potential benefits of exceeding the standard (other indications) maximum dose are associated with a theoretically more rapid therapeutic effect [15]; however, pulses are the treatment of choice in situations requiring urgent intervention with the use of glucocorticoids, when an immediate clinical effect is needed (see below). Until optimal therapy is established based on international studies (including the Best Available Treatment Study, BATS), we suggest that the decision to exceed the daily dose equivalent to $60 \mathrm{mg}$ of prednisolone is made individually. Furthermore, doses of GCs based on calculated IBW should be considered in overweight and obese patients.

Methylprednisolone pulses of 10-30 $\mathrm{mg} / \mathrm{kg} / \mathrm{dose}$ (maximum daily dose of $\mathbf{1 0 0 0} \mathbf{~ m g}$ ) given for 3-5 consecutive days are an alternative form of steroid therapy [10]. Pulse steroid therapy should be used in patients in shock, with a severe or rapidly deteriorating general condition (especially in the case of multiorgan failure), signs of macrophage activation syndrome (see below), as well as in those with no satisfactory outcomes of GC treatment in a standard $2 \mathrm{mg} / \mathrm{kg} /$ day regimen. Methylprednisolone pulses should be administered as a 1-hour infusion. Treatment should be continued with methylprednisolone at a dose of $2 \times 1 \mathrm{mg} / \mathrm{kg}$ or an equivalent dose of another GC until CRP normalizes, after which an oral steroid may be included, and the dose can be gradually reduced over 2-3 weeks.

5.4.3. Third-line treatment uses biologic agents: anakinra (an inhibitor of the IL-1 receptor), tocilizumab (an inhibitor of the IL-6 receptor), and infliximab (an inhibitor of the TNF- $\alpha$ ) $[10,11]$. If third-line treatment of patients with Kawasaki disease phenotype is needed, infliximab is indicated in the first place $[10,13$, 14]. In the remaining cases, it has not been clearly established which of the above agents is the third-line agent of choice [10]. Table 4 summarises third-line immunomodulatory therapy in children with MIS-C. 


\subsection{Antiplatelet and anticoagulant therapy}

Patients with MIS-C tend to develop thrombosis and show laboratory signs of bleeding disorders [18]. Furthermore, antiplatelet or anticoagulant therapy is indicated due to haemodynamic disturbances and the risk of coronary aneurysms. So far, there is no strong evidence for the superiority of any therapy over others.

5.5.1. Patients whose clinical and laboratory findings support the diagnosis of Kawasaki disease (see Table 2) should receive acetylsalicylic acid (ASA) under the current recommendations: at an initial dose of $30-50 \mathrm{mg} / \mathrm{kg} /$ day in 4 divided doses, with dose reduction to $3-5 \mathrm{mg} / \mathrm{kg} /$ day in a single dose 48 hours after fever resolution [13, 14]. Continuation of ASA treatment at an anti-inflammatory dose in children on GCs seems unjustified due to the much stronger anti-inflammatory effects of glucocorticoids and an unfavourable benefit-risk ratio (increased risk of GI bleeding [19]); therefore, we suggest reducing the dose of ASA to an antiplatelet dose.

5.5.2. Other MIS-C patients should receive ASA at an antiplatelet dose of 3-5 mg/kg (maximum dose $75 \mathrm{mg} /$ day) for at least 6 weeks (until coronary artery lesions are excluded in follow-up ECHO) (10).

5.5.3. Treatment with aspirin should be avoided in patients with active bleeding, high risk of bleeding, or a platelet count $\leq 80000 / \mu$ l.

5.5.4. Anticoagulant/antiplatelet therapy in children with coronary aneurysms should follow the recommendations for KD (14).

5.5.5. Indications for the use of anticoagulants (most often low-molecular-weight heparin) and their dosage should be set individually. The following factors should be considered when deciding on anticoagulant therapy: prolonged immobilization, low ejection fraction $(<35 \%$ in particular), the presence of giant aneurysms, obesity, and other findings that may indicate the risk of thromboembolic complications.

\subsection{Additional therapeutic considerations}

Some patients with MIS-C develop Macrophage Activation Syndrome (MAS). MAS should be considered when planning immunomodulating therapy. A multidisciplinary consultation (including a rheumatologist and a clinical immunologist) is recommended.

\section{Special clinical circumstances}

\subsection{Spontaneous improvement}

A spontaneous resolution of symptoms and inflammation is observed in some patients: this is seen in children whose disease resolves in the first week or in those diagnosed late. At this moment, there are insufficient data to propose clear recommendations for the management in such patients, and decisions about immunomodulatory treatment should be made individually, preferably by a multidisciplinary team, and should be based on the benefit-risk evaluation.
We recommend that all of the following conditions are met during treatment:

a. cardiac monitoring in accordance with the abovedescribed guidelines,

b. the use of ASA at 3-5 mg/kg for at least 6 weeks, until coronary lesions are excluded,

c. withdrawal of immunomodulatory treatment depending on:

- marked improvement in the child's general condition and absence of any new symptoms of the disease,

- resolution of fever,

- normalization of inflammatory markers and other significant laboratory abnormalities,

- normal cardiac tests: ECG and ECHO performed 5 days after the onset of symptoms.

\section{Post-hospital follow-up}

The decision on the patient's discharge should be made individually, taking into account the clinical picture and the severity of the disease. In our opinion, the following considerations should be taken into account when making a decision on discharge:

- resolution of fever for at least 48 hours and the absence of any new disease symptoms, such as rash, conjunctivitis, or manifestations from other tissues and organs,

- resolution of symptoms of internal organ failure,

- marked improvement in inflammatory markers,

- a trend towards normalization of abnormal laboratory values, including serum albumin, D-dimers, platelet count, etc.,

- normalization of $\mathrm{EF} \geq 55 \%$.

The child's parents/guardians should be instructed that if symptoms recur, they should immediately report to hospital.

7.2. Furthermore, exemption from sports and physical education is recommended:

- for 6 weeks in all children,

- in patients with coronary lesions - until coronary images normalize (ASA treatment should be continued until this time),

- in patients with myocardial damage, at least until normalization of troponin I levels (detailed recommendations to be given by a consultant cardiologist).

7.2.1. Holter ECG may be performed before resuming sports activities in patients with arrhythmias.

7.2.2. Patients practicing professional sports as well as highly traumatic and contact amateur sports require a separate, individual specialist qualification (specialists in cardiology and sports medicine). Contraindications to this type of activity include: antiplatelet or anticoagulant therapy, persistent coronary changes, post-inflammatory stenosis, impaired myocardial perfusion, persistent arrhythmias, and heart failure in particular.

7.3. In the case of persistent abnormalities after the disease, at least 6 weeks of medical supervision over 
the patient is recommended. The scope of follow-up visits should be adjusted to the patient's condition, disorders observed in the course of the disease, and possible adverse effects of treatment (steroid therapy in particular), and it should not be limited to cardiac consultations.

We encourage reporting each patient with MIS-C in the national register of paediatric inflammatory diseases during the COVID-19 pandemic (MOIS CoR Study). An analysis of a large group of patients will allow us to obtain the full clinical picture of children with MIS-C in Poland to assess the efficacy of treatment used and the late consequences of the disease.

You can report your patients here: www.pimsudzieci.pl You can contact us here: covidudzieci@gmail.com

\section{DISCLOSURE}

The authors declare no conflict of interest.

\section{REFERENCES}

1. Riphagen S, Gomez X, Gonzalez-Martinez C, et al. Hyperinflammatory shock in children during COVID-19 pandemic. Lancet 2020; 395: 1607-1608.

2. Royal College of Paediatrics and Child Health: Guidance. Paediatric multisystem inflammatory syndrome temporally associated with COVID-19. https://www.rcpch.ac.uk/sites/default/files/2020-05/ COVID-19-Paediatric-multisystem-\%20inflammatory\%20syndrome-20200501.pdf Data wejścia 19.11.2020.

3. Whittaker E, Bamford A, Kenny J, et al. Clinical Characteristics of 58 Children with a Pediatric Inflammatory Multisystem Syndrome Temporally Associated With SARS-CoV-2. JAMA 2020; 324: 259-269.

4. Godfred-Cato S, Bryant B, Leung J, et al. COVID-19-Associated Multisystem Inflammatory Syndrome in Children - United States, March-July 2020. MMWR Morb Mortal Wkly Rep 2020; 69: 10741080.

5. Clark BC, Sanchez-de-Toledo J, Bautista-Rodriguez C, et al. Cardiac Abnormalities Seen in Pediatric Patients During the SARS-CoV2 Pandemic: An International Experience. J Am Heart Assoc 2020; 9: e018007.

6. Okarska-Napierała M, Ludwikowska KM, Szenborn L, et al. MOIS CoR Study Group. Pediatric Inflammatory Multisystem Syndrome (PIMS) Did Occur in Poland during Months with Low COVID-19 Prevalence, Preliminary Results of a Nationwide Register. J Clin Med 2020; 9: 3386.

7. World Health Organization. Multisystem inflammatory syndrome in children and adolescents temporally related to COVID-19. https://www.who.int/publications/i/item/multisystem-inflammatory-syndrome-in-children-and-adolescents-with-covid-19. [Access: 20.11.2020].

8. Centers for Disease Control and Prevention. Information for Healthcare Providers about Multisystem Inflammatory Syndrome in Children (MIS-C). https://www.cdc.gov/mis-c/hcp/. [Access: 20.11.2020].

9. Loke YH, Berul CI, Harahsheh AS. Multisystem inflammatory syndrome in children: Is there a linkage to Kawasaki disease? Trends Cardiovasc Med 2020; 30: 389-396.
10. Harwood R, Allin B, Jones CE, et al.; PIMS-TS National Consensus Management Study Group. A national consensus management pathway for paediatric inflammatory multisystem syndrome temporally associated with COVID-19 (PIMS-TS): results of a national Delphi process. Lancet Child Adolesc Health 2020; S23524642(20)30304-7.

11. Henderson LA, Canna SW, Friedman KG, et al. American College of Rheumatology Clinical Guidance for Multisystem Inflammatory Syndrome in Children Associated With SARS-CoV-2 and Hyperinflammation in Pediatric COVID-19: Version 1. Arthritis Rheumatol 2020; 72: 1791-1805.

12. Marczyńska M, Pokorska-Śpiewak M, Talarek E, et al. Postępowanie z dzieckiem z COVID-19. Polskie Towarzystwo Pediatryczne. Zalecenia dla pediatrów oraz lekarzy medycyny rodzinnych rodzinnej w Podstawowej Opiece Zdrowotnej oraz dla leczących dzieci zakażone SARS-CoV-2 w warunkach szpitalnych. Przeg Ped 2020; 49: 1-7.

13. de Graeff N, Groot N, Ozen S, et al. European consensus-based recommendations for the diagnosis and treatment of Kawasaki disease the SHARE initiative. Rheumatology (Oxford) 2019; 58: 672-682.

14. McCrindle BW, Rowley AH, Newburger JW, et al.; Kawasaki Disease Committee of the Council on Cardiovascular Disease in the Young; Council on Cardiovascular and Stroke Nursing; Council on Cardiovascular Surgery and Anesthesia; and Council on Epidemiology and Prevention. Diagnosis, Treatment, and LongTerm Management of Kawasaki Disease: A Scientific Statement for Health Professionals From the American Heart Association. Circulation 2017; 135: e927-e999.

15. Lösel R, Wehling M. Nongenomic actions of steroid hormones. Nat Rev Mol Cell Biol 2003; 4: 46-55.

16. Roberts SC, Jain S, Tremoulet AH, et al. The Kawasaki Disease Comparative Effectiveness (KIDCARE) trial: A phase III, randomized trial of second intravenous immunoglobulin versus infliximab for resistant Kawasaki disease. Contemp Clin Trials 2019; 79: 98-103.

17. UpToDate. Anakinra: Drug Information. https://www-1uptodate1com-100022chb0c10.han3.wum.edu.pl/contents/anakinra-drug-information? sectionName $=$ Pediatric\&topicId $=9246 \&$ search $=$ anakinra\&usage_type $=$ panel \&anchor $=$ F16330957\&source $=$ panel_ search_result\&selected Title $=1 \sim 105 \& \mathrm{kp} \_t a b=$ drug_general $\&$ display_rank=1\#F16330957. Data wejścia 20.11.2020.

18. Brodin P. Immune determinants of COVID-19 disease presentation and severity. Nat Med 2020; 27: 28-33.

19. Masclee GM, Valkhoff VE, Coloma PM, et al. Risk of upper gastrointestinal bleeding from different drug combinations. Gastroenterology 2014; 147: 784-792e9. 